\title{
METHODS AND PRINCIPLES OF PRODUCT DESIGN FOR SMALL-SCALE PRODUCTION BASED ON 3D PRINTING
}

\author{
Salobir, Jure; Duhovnik, Jože; Tavčar, Jože \\ University of Ljubljana
}

\begin{abstract}
Technology of 3D printing is opening the possibility for small-scale production in quantities between ten and several hundred pieces. The technology of adding material enables the production of complex and integrated functional concepts in a single-pass process, which consequently potentially reduces the need for assembly operations. Design approaches and manufacturing processing are not mastered well because of a constant stream of new materials and manufacturing options. Well-designed products need to consider attributes of 3D printing as early as the conceptual phase. The cost of the product can be reduced with a systematic research and considering principles for small-scale production. In a cheaper, alternative production process the quality range of products is often lower. It has to be compensated with appropriate construction solutions which are less tolerance-sensitive. Therefore, in order to support the designer, to reduce the costs and design time of the product, a computer program was created to provide the user with an insight into the appropriate 3D printing technology. For simplifying the use, the program is also integrated into the product development process.
\end{abstract}

Keywords: Computer software, Small-scale production, 3D printing, Design for Additive Manufacturing (DfAM), New product development

Contact:

Salobir, Jure

University of Ljubljana

Faculty of Mechanical Engineering

Slovenia

salobir.jure@gmail.com

Cite this article: Salobir, J., Duhovnik, J., Tavčar, J. (2019) 'Methods and Principles of Product Design for SmallScale Production Based on 3D Printing', in Proceedings of the 22nd International Conference on Engineering Design (ICED19), Delft, The Netherlands, 5-8 August 2019. DOI:10.1017/dsi.2019.83 


\section{INTRODUCTION}

Clients often demand small-scale products in quantities between ten and several hundred pieces. These are special products for niche markets or adapted products for individual clients' requests. Additionally, there are radically new products with bigger potential, but the investment in mass production is risky. It is better to test the market with a small scale series first and later upgrade the product according to the customers' response. Realisation of a creative idea into a product that is sent to the market needs capital and a reliable production partner. Small-scale production enables designers and owners of small businesses to operate within their capabilities. The small-scale approach involves everything from an overview of the quantities of materials to the supplies that are being procured, which leads to the decision on how many products the production can generate. Small-scale production checks the market and customer's feedback more effectively, reduces the risk of excess inventory, can lead to a more agile supply chain, and provides smaller lead teams. At the same time, the product is sent to the market faster, and reduced production costs enable a faster flow of profit while attracting many smaller small-scale producers who are willing to invest their time, resources and expert knowledge (Holmström, 2010). Over the last decade, agile development approach has received much attention from researchers and practitioners as an approach to deal with project development in an innovative and dynamic environment. A core principle of Agile development is to satisfy the customer by providing valuable product on an early and continuous basis. The agile method aims to deliver a small set of features/working modules to the customers as quickly as possible in short iterations. This reduces much of upfront research and analysis required by traditional methodologies (Gurusamy et al., 2016)

Both iterative and agile methods were developed to overcome the various obstacles faced in sequential forms of project organization. As technology projects grow in complexity, it is difficult for users to define the long-term requirements. Projects developed by constant iterations (agile) can provide an opportunity for clients/users to provide feedback to help refine their requirements. However, integrating Design Thinking into the agile iterations overcome the challenges posed by Agile methodology and can contribute to deliver constant continuous deliveries to the customers faster than the traditional approach. (Gurusamy et al., 2016)

The technology of adding materials, commonly known as 3D printing, is currently being promoted as the spark for a new industrial revolution. Technology allows an individual to produce customized products without causing additional production costs. Additive manufacturing (AM) enables the production of complex and integrated functional concepts in a single-pass process, which consequently potentially reduces the need for a composite part and assembly operations (Weller et al., 2015).To receive the full benefits of additive manufacturing, designers must learn to think differently while focusing on creating robust industrial solutions with added value. Design theories, processes, methods, tools, and techniques must be adapted or developed to address the inherent coupling between material, geometry, and quality in these systems. Specialized and application-specific tools must be developed to support the design of cellular structures, meta materials, heterogeneous artifacts, biological scaffolds, and more. Finally, it must be acknowledged that each build is a design artifact with its own requirements and constraints, and its own features to be designed and optimized. Thus DfAM (Design for Additive Manufacturing) must extend beyond the product to the production system and consider the entire value chain (Thompson et al., 2016).

The purpose of this article is to introduce the design aspect of the small-scale production. The product engineering design is very important for the optimal function of the final piece. Taking into consideration all of the above, it is possible to significantly reduce production costs in small-scale productions (Jacob et al., 2018). Our goal is to present design principles for small-scale production with various AM technologies and with help of software to enhance designers' thinking freedom to overcome constraints of traditional manufacturing technologies.

In the field of polymers and composites, design approaches and manufacturing processing are not mastered well because of a constant stream of new materials and technologies. Individual innovative solutions are frequently used only in limited circles. With a systematic research and specific principles for small-scale production, the cost of the finished product can be reduced. In an alternative production process the quality range of finished products is often lower. It has to be compensated with appropriate construction solutions, which are less tolerance-sensitive. Therefore, in order to simplify the work of 
the designer and to reduce the design time of the product and the cost of the design, a computer program called "3D-Advise" was created to provide the designer with an insight into the appropriate AM technology, its advantages, weaknesses and structural recommendations, while designing the product for the selected technology.

Information in "3D-Advise" is a selected collection from different sources, data from AM providers, comprehensive literature review, and internet sources. The first version of the program is ready. We are planning to regularly update the database with new data and concurrently test applicability by end users. According to the feedback from test users we will upgrade the application. The ambition of the "3D-Advise" is to support product developers with a wide range of AM technology data. Our contribution is to prepare data and integrate support into product development process in a way that will stimulate designers creativity and efficiency at product development.

\section{ADDITIVE MANUFACTURING, SMALL-SCALE PRODUCTION AND PRODUCT DEVELOPMENT}

Many entrepreneurs and bigger companies face the challenge of producing an item in a smaller quantity for an acceptable cost. Additive or subtractive manufacturing is generally less productive and therefore less cost-effective than forming technologies. The main obstacle in material forming technologies is the initial investment in the tool itself. A vast number of rapid prototyping processes offer new opportunities every day, however twenty or fifty pieces already represent a limit because of the low productivity or cost of on individual item. The mechanical characteristics of the prototype and surface quality are also an important limitation. A large palette of materials and technologies exist which are suitable for small-scale production in their current or slightly-adapted form. Some materials (polymers, metals) are completely established and known in applications, while for example ceramics, newer composites or some natural materials are still fairly unexplored and rarely used in applications. The most prominent trend - direct digital production - explores the use of additional production technologies, such as AM (Chen et al., 2015). Additive technologies fall into the category of advanced manufacturing technologies required for mass adaptation (Duray et al., 2000) because of their specific production capacities, such as flexibility and speed (Deradjat \& Minshall, 2017). The potential of AM actually lies in the fact that it largely reduces the time interval between equipment changes on a largescale production line, and allows for frequent innovations on an item during the manufacturing process (Yeh \& Chen, 2018). Although AM is a collection of digital manufacturing technologies, the speed of its adoption has not been quite what the market has expected (Yeh \& Chen, 2018).

Model of the product development process helps us understand and compare procedures in different types of production, and thus find the most appropriate methods for an enterprise (Duhovnik \& Tavčar, 2015). This is why the first step in designing a computer program for design consulting through AM was to place it in the actual process. Diagram based on that model and modelled for our purpose is presented in Figure 1. Concurrent engineering principles are included in several iterations or loops (Zadnik et al., 2009). The process begins with identifying the needs of the client. The interdisciplinary team, which has members from different areas depending on the product and used technology, prepares the description of needs for a clear definition of requirements (Duhovnik et al., 2006). Recognizing problems and identifying them are a precondition for a clear definition of goals. This is done in the first loop (invention loop) of the process. The 3D-Advise connects with the first loop by asking the user for a description of needs and a specific definition of requirements. When using the 3D-Advise, the user needs to know what the intended product requirements are (material, tolerances, cost, etc.), and whether AM is appropriate at all. These decisions then lead to the second loop of the process, which upgrades the process of purifying the objectives so that we have a more precise task, requirements and wishes in the conditions of planning the process, the qualifications of the development and construction group, the levels of construction and the conditions of the environment. In the third loop, a certain, usually ad-hoc development-construction group, needs to specify the requirements that are the basis of the construction process. 


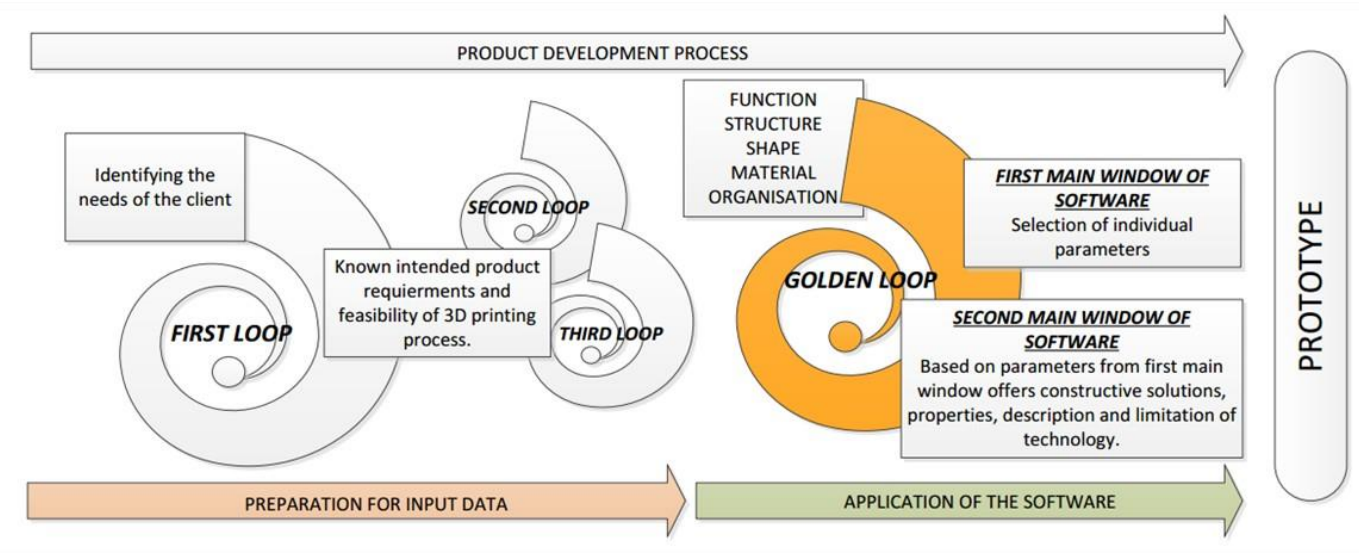

Figure 1. Model of product development process based on iteration loops.

A product is defined with basic data, such as function, shape and its structure. Material is a dependent parameter, which defines the volume and capability of the product in different environments. If the complexity of a product is increasing from a simple mechanical element or structure to a complex system with the parameters of function, structure, shape, material, and organisation, all those five parameters define the product. The interaction between the five parameters is happening inside the golden loop (Duhovnik \& Tavčar, 2015). This is where the use of the computer program for design consulting through AM is the most meaningful. When determining or choosing technology, the 3DAdvise offers design solutions for the selected technology. Thus the designer can achieve the desired result faster (in a small number of iterations) in the design process with the offered options. Here, the main windows of the 3D-Advise software are strongly connected. In the first, the selection of individual parameters takes place, while the second one, depending on the selected parameter, offers constructive solutions, the description of the process, the limitations and good properties of the technology. As the construction process takes place in a golden loop, it has been misinterpreted several times as the main process. It is essential that the conquering of the product is understood comprehensively, from the identification of the idea, development, to the design (by making and testing) of the prototype.

The latter explanation can easily be connected with yet another view on product development. Increasingly uncertain market requirements and faster-paced innovation cycles have led to a paradigm shift towards Agile product development, which are based on the Agile Manifesto. (Schuh et al., 2018) As more electronic hardware and software are incorporated into traditional mechanical products, manufacturers are seeking better ways to integrate design activities across engineering disciplines. As a result, many design and development practices are exchanged.

Agile software development is a group of software development methods based on iterative and incremental development, where requirements and solutions evolve through collaboration between self-organizing, cross-functional teams. It promotes adaptive planning, evolutionary development and delivery, and a time-boxed iterative approach, and encourages rapid and flexible response to change. It is a conceptual framework that promotes foreseen interactions throughout the development cycle. By applying AM technologies in product development cycle the principles of agile development can be implemented also at development of physical objects.

The engineering design must be carefully planned and systematically executed. In particular, engineering design methods must integrate the many different aspects of designing and the priorities of the end-user (Pahl et al., 2007). All phases of the product lifecycle need to be taken into account during the planning and conceptual design phases, while the entire product family and possibilities for upgrading also need to be envisaged. Expected results are better products and a reduced number of changes in later phases of the process development, and especially after production launch (Prasad, 1996).

\section{ENHANCING PRODUCT DESIGN FOR ADDITIVE MANUfACTURING}

In recent years, there has been a high scientific production on additive manufacturing issues, and the application and possibilities of these technologies have been analysed and improved from very different fields and industries. All these aspects are of interest in both productive and educational 
contexts. This way, optimization software has a key role and choosing the suitable tool is critical (Garcia-Dominguez et al., 2017). The designed computer program is primarily intended for the designer as a support at designing of a product. The 3D-Advise is made in the C\# programming language on Windows Presentation Foundation (WPF), which is a modern Windows graphical display system (MacDonald, 2012). Code was written in Microsoft's Visual Studio 2017 software (Community version).

3d-Advise software targets those users, who wants to check the market and possibly run small batch production, without huge investment in equipment. The goal is, that software covers as many technologies as possible, to give the user proper insight in what direction should the project go. Based on info, that is provided by using the software, user can decide for going forward with design, possible investment, or he can recheck data, do additional research and possibly think about manufacturing item by service company.

The 3D-Advise comprises two main windows. The first window (Figure 2) is used to select the AM technology and afterwards opens the second window where this technology is described (Figure 3). The software relies heavily on the aforementioned product development process, as it covers the loops of product development process with its operation. Knowledge, ideas and requirements cover the first loop (invention loop); the second and third loops (system engineering loop and research loop) are connecting the first loop to golden loop which is covered by the elective part of the software, filtration and the details of individual technologies (descriptions, operation, construction guidelines).

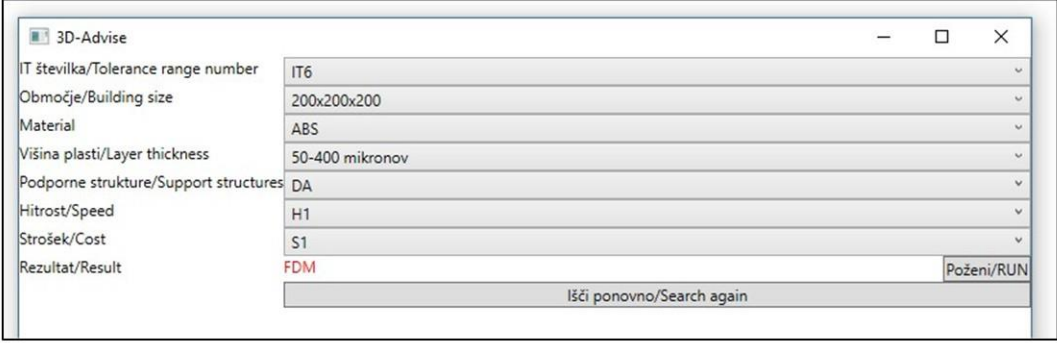

Figure 2. Main software window of 3D-Advise.

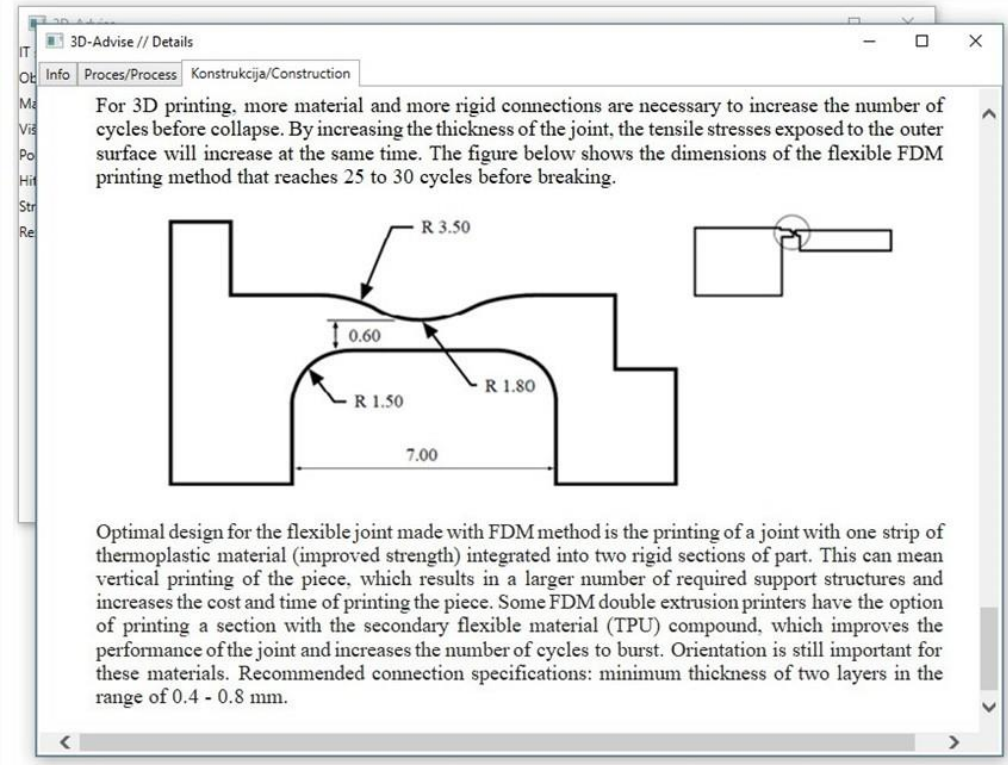

Figure 3. Detail software window of 3D-Advise.

The 3D-Advise enable user-friendly searching and presentation of required information. In the first step the AM technology is selected according to the requests set by designer as shown in Figure 4. In the next step each AM technology contains detailed information on materials, tolerances, speeds, costs, etc. Information is stored in the database managed by computer program. The user currently has the option of selecting seven parameters (IT classes or tolerances, building size, material, layer 
thickness, support structures, speed, cost), which connect to individual technologies with their values. Technologically specific values are mutually exclusive. Currently, the 3D-Advise includes only limited number of parameters for individual technologies that, according to the ISO / ASTM 52915: 2016 (en) standard, fall under the following categories: (ISO/ASTM, 2016)

- VAT Photopolymerisation

- $\quad$ Material Jetting

- $\quad$ Binder Jetting

- $\quad$ Powder Bed Fusion

- Material Extrusion

- Direct energy deposition

- Lamination

The abovementioned categories of Additive Manufacturing, are divided into versions. For example, VAT Photopolymerisation divides into Stereolitography (SLA), Direct Light Processing (DLP) and Continuous Direct Light Processing (CDLP). The contents below take into account all variations.

While AM seems to have unlimited potential, it does not have unlimited capabilities. Designers must take into account many types of constraints, including those associated with CAD and the digitization of their ideas; the digital and physical discretization of the parts to be produced; the characteristics of AM processes and the current capabilities of AM machines; the impact of AM processing on material properties and the requirements for processing materials using various AM techniques; new challenges and requirements associated with metrology and quality control; through-life requirements and considerations such as maintenance, repair and recycling; and external factors including the regulatory environment (Thompson et al., 2016). One of the objectives of 3D-Advise software is to simplify and speed up the design process through these constraints.

One of the biggest issues of software is adding new materials and new AM machines characteristics, that are continuously becoming available on the market due to continuous research and development. For the program to evolve and improve, there is a need for feedback and further demands from user to programmer. The "Info" box in flowchart application is link between user and programmer. There is an issue in terms of communication between various user and programmer. In later phases, the program will contain an option to manually expand the database including materials, new technologies, additional guidelines, that are discovered as a lesson learned process or during research. This leads to the conclusion, that each user evolves their program in terms of their needs. Still the support of programmer will be needed for bugs, additional options etc. which can be easily communicated via internet communicating options, for example: feedback on web site, forum, e-mail. In the final stage WEB base version of the 3D Advise will be needed with continuous development and support. Only central maintenance of application can guaranty regularly updated information.

More than 80 pages of the research reports are included in the software, from more than 100 reviewed sources and references. Each of the technologies has, in addition to the descriptions of characteristics, process and construction guidelines, included seven search parameters. There is a plan to update the set of AM printing parameters according to experiences that will be accumulated during testing period. Additive Manufacturing provides lots of benefits due to the layer by layer manufacturing. Thereby, one of Additive Manufacturing's most important potentials is the capability to extend the design freedoms. To make these benefits accessible to different user groups, design rules for Additive Manufacturing were developed within the project "Direct Manufacturing Design Rules". Design rules provide suitable ranges within which standard elements attribute values can be varied in order to receive best qualities (Adam \& Zimmer, 2014).

The goal is to define optimal set of parameters for each printing technology that are necessary for part design. In addition to materials, speed, tolerances and other parameters, cost is also another crucial aspect for understanding the success of AM. It is calculated on the basis of different factors, including the fixed cost of printing resources, usage cost, and the cost for the technological maintenance of the current infrastructure. Also, AM implementation is associated with various forms of related investment, including investment into hardware, software, or system integration (Baumers et al., 2016). 


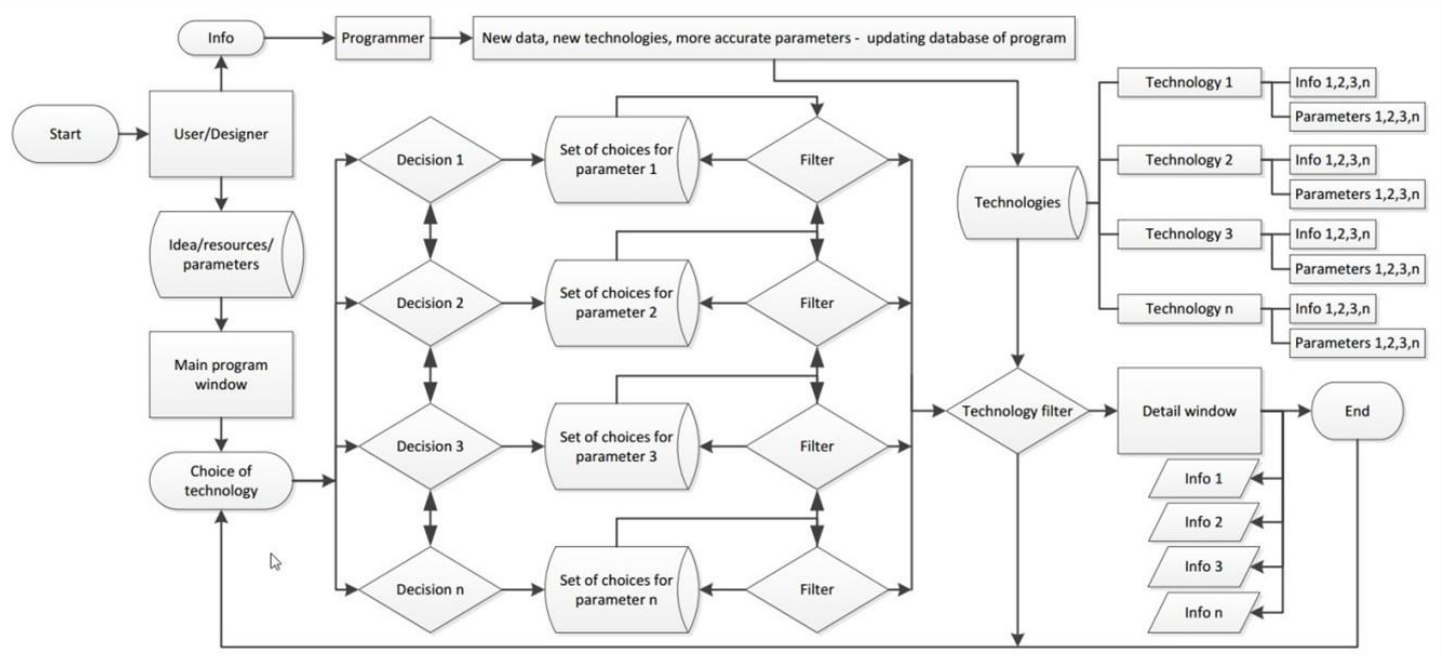

Figure 4. Software flowchart.

When selecting individual parameters, the 3D-Advise automatically filters and extracts data which, in combination with the selected parameters, is not possible. When selecting a combination of parameters, the software automatically shows the appropriate AM technology. A new technology search can be launched, or the proposed option can be confirmed. Upon confirmation, the 3D-Advise outlines the details of the technology, the description of the process, and the design recommendations for designing the product with the envisaged technology. The operation of the software and details are presented in the following diagrams (Figure 4 \& Figure 5).

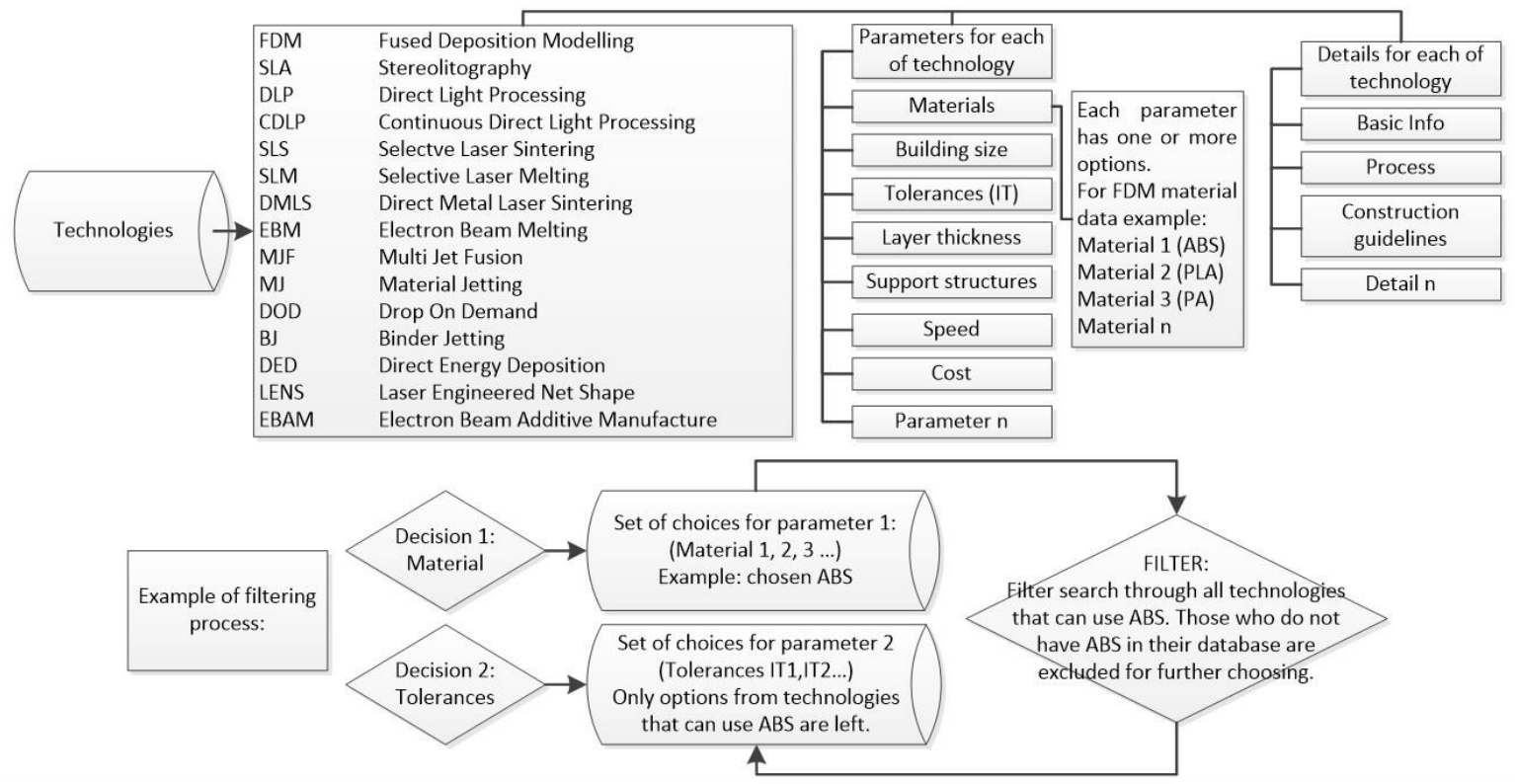

Figure 5. Software flowchart details.

The most important part of the software is the second main window, which gives the constructor information about the selected technology (Figure 3). All shown data comes in HTML format and are not configured by program, the text is pre-defined based on done research. As mentioned above, the program provides guidelines, which can be used for faster and therefore cheaper approach for part design and manufacturing. It must be noted, that following inserted guidelines does not lead to final optimised product, but just speed up the process. 


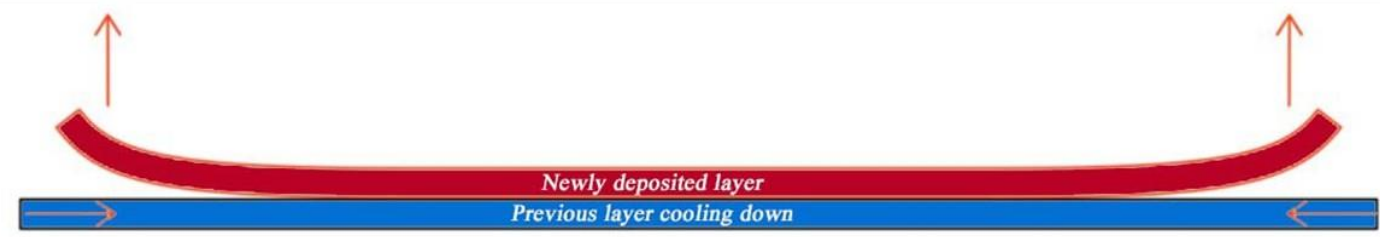

Figure 6. Shrinkage of lower layers and pulling of upper layers up due to cooling.

For example, when describing the selected technology in the first pane (Info), the 3D-Advise provides data to the designer about the advantages and disadvantages of the technology. The problem of twisting the piece during manufacture with the Fused Deposition Modelling technology can be highlighted as an example when the underlying layers are shrinking and the newly deposited layer is drawn upwards due to cooling (Figure 6). The user also receives information about other suitable materials and their properties, as well as application examples.

The second pane (Process) gives the user an insight into the operation of the selected technology. There is a step-by-step description supported by the image material (Figure 7) and the main components of the printer, as well as a description of the basic characteristics of the technology.

In the last pane (Construction), the construction guidelines for the selected technology are presented. The construction guidelines include information on how to design a product for a particular technology. They treat wall thickness, addition of radius or rounding, suitable distances between components, screw holes, thickening, etc. and are also recorded in value. Additionally, constructive bookmarks have been added to provide information on the best example of the use of each of the aforementioned features. Examples are presented in Table 1.
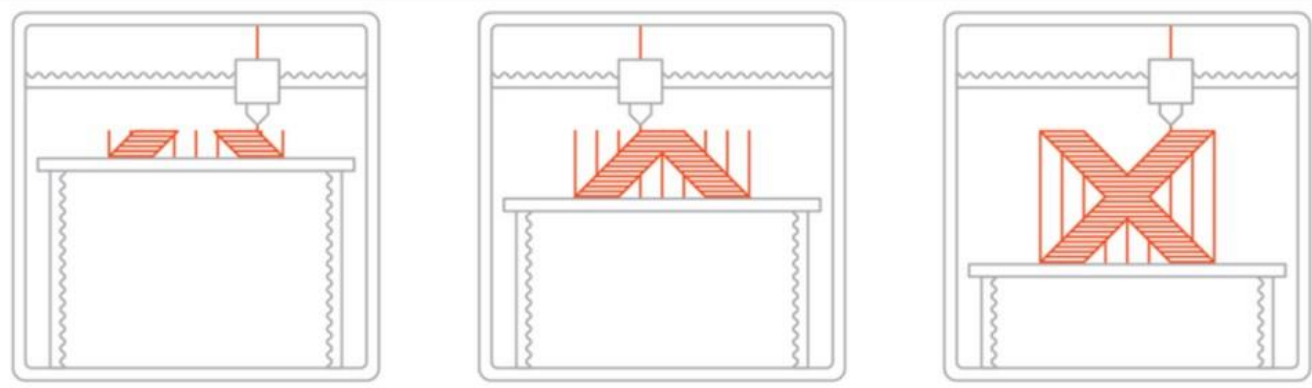

Figure 7. FDM process ${ }^{1}$

In the last pane (Construction), the construction guidelines for the selected technology are presented. The construction guidelines include information on how to design a product for a particular technology. They treat wall thickness, addition of radius or rounding, suitable distances between components, screw holes, thickening, etc. and are also recorded in value. Additionally, constructive bookmarks have been added to provide information on the best example of the use of each of the aforementioned features. Examples are presented in Table 1.

Table 1. Examples of construction guidelines for FDM technology

Wall thickness: for all walls of the housing (enclosures), a minimum wall thickness
of $2 \mathrm{~mm}$ is recommended.

${ }^{1}$ source: https://www.3dhubs.com/knowledge-base/introduction-fdm-3d-printing 


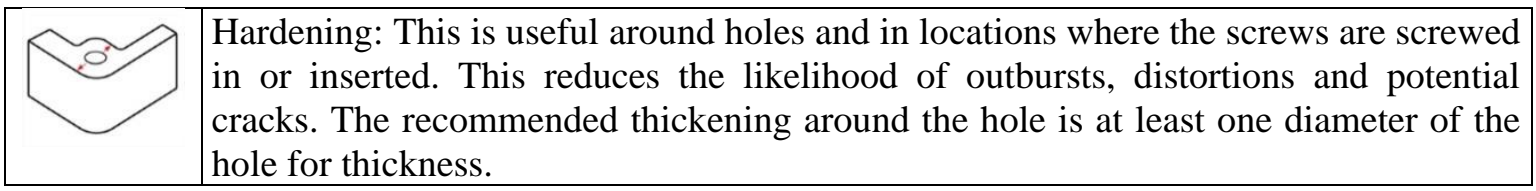

Another important topic is the assembly of pieces or individual components (screw connections, snapfit links, etc.) and also the use of fillers, nets and their geometry. Additive manufacturing can create three-dimensional lattices and trusses with specific mechanical, thermal, optical, and biological properties. For example, AM lattices can be used to produce high stiffness low weight structures and photonic crystals. Lattices and trusses can be incorporated into sandwich structures or used to line external surfaces for increased strength Finally, AM can directly produce assemblies with moving or movable parts such as crank and slider mechanisms, gears, joints and hinges. However, assemblies and interlinked structures require a clearance between the individual bodies during fabrication. They also require any remaining interstitial material to be removed when completed. (Thompson et al., 2016).

The field of guidelines is set quite broadly for the purpose of faster and consequently cheaper work of the constructor or the user. As already mentioned in the selection criteria of individual technologies, it is also necessary to expand the database of the software with novelties.

\section{SUMMARY}

$\mathrm{AM}$ is on the rise and it is developing very quickly. Despite the rapid development and increasing accessibility, users or designers nevertheless often encounter restrictions in individual technologies. The computer program, which is connected with the design process, makes it easier to move from an idea to the final product. It reduces the time needed to design and manufacture, and consequently reduces costs. With increasing digitalization and availability of additive technologies, it is important that adequate support is provided for the use of such technology. A 3D-Advise software was created to provide the product designers with an insight into the appropriate AM technology. Such softwares are of utmost importance to product developers. The collected data will be used as a initial starting point for further research, while the progress and changes in technologies are to be checked continually through recent literature, and the database of the software kept up to date.

\section{REFERENCES}

Adam, G. A. and Zimmer, D. (2014), "Design for additive manufacturing - element transitions and aggregated structures", Cirp Journal of Manufacturing Science and Technology, Vol. 7, pp. 20-28. https://doi.org/10.1016/j.cirpj.2013.10.001

Baumers, M., Dickens, P., Tuck, C. and Hague, R. (2016), “The cost of additive manufacturing: machine productivity, economies of scale and technology-push", Technological Forecasting and Social Change, Vol. 102, pp. 193-201. https://doi.org/10.1016/j.techfore.2015.02.015

Chen, D., Heyer, S., Ibbotson, S. and Salonitis, K. (2015), "Direct digital manufacturing: definition, evolution, and sustainability implications", Journal of Cleaner Production, Vol 107, pp. 615-625. https://doi.org/10.1016/j.jclepro.2015.05.009

Deradjat, D. and Minshall, T. (2017), "Implementation of rapid manufacturing for mass customisation”, Journal of Manufacturing Technology Management, Vol. 28 No. 1, pp. 95-121. https://doi.org/10.1108/JMTM-012016-0007

Duhovnik, J., Kušar, J., Tomaževič, R. and Starbek, M. (2006), “Development process with regard to customer requierments", CE Concurrent Engineering: Research and Applications, Vol. 14, pp. 67-82. https://doi.org/10.1177/1063293X06064149

Duhovnik, J. and Tavčar, J. (2015), "Concurrent Engineering in Machinery”, In: Concurrent Engineering in the 21 st Century. s.1.: Springer International publishing, p. 839. https://doi.org/10.1007/978-3-319-13776-6_22

Duray, R., Ward, P. T., Milligan, G. W. and Berry, W. L. (2000), “Approaches to mass customization: configurations and empirical validation”, Journal of Operations Management, Vol. 18 No 6, pp. 605-625. https://doi.org/10.1016/S0272-6963(00)00043-7

Garcia-Dominguez, A., Claver, J. and Sebastian, M. (2017), "Study for the selection of design software for 3D printing topological optimisation”, Procedia Manufacturing, Vol. 13, pp. 903-909. https://doi.org/10.1016/j.promfg.2017.09.155

Gurusamy, K., Srinivasaraghavan, N. and Adikari, S. (2016), “An Interated Framework for Design Thinking and Agile Methods for Digital Transformation", In: Design, User Experience and Usability: Design Thinking and Methods: 5th International Conference, Toronto: s.n., pp. 34-42. https://doi.org/10.1007/978-3-31940409-7_4 
Holmström, J. (2010), "Rapid manufacturing in the spare parts supply chain: alternative approaches to capacity deployment”, Journal of Manufacturing Technology Management, Vol. 21 No. 6, pp. 687-697. https://doi.org/10.1108/17410381011063996

ISO/ASTM, (2016), ISO/ASTM 52915:2016(en) Specification for additive manufacturing file format (AMF) Version 1.2, s.l.: ISO/ASTM.

ISO-286, (2010), ISO 286-1:2010. s.1.:s.n.

Jacob, A., Windhuber, K., Ranke, D. and Lanza, G. (2018), "Planning, evaluation and optimisation of product design and manufacturing technology chains for new product and prodution technologes on the example of additive manufacturing", Procedia CIRP, Vol. 70, pp. 108-113. https://doi.org/10.1016/j.procir.2018.02.049

MacDonald, M. (2012), Pro WPF 4.5 in C\#, Windows Presentation Foundation in .NET 4.5, s.1.: Apress.

Pahl, G., Beitz, W., Feldhusen, J. and Grote, K.-H. (2007), Engineering Design - A Systematic Approach, s.l.: Springer.

Prasad, B. (1996), Concurrent Engineering Funamentals: Integrated Product and Process Organization, Vol. 1. s.1.: Pearson Education (US). https://doi.org/10.13140/rg.2.1.2613.0005

Schuh, G., Rebentisch, E. and Dölle, C. (2018), "Defining scaling strategies for the improvement of agility performance in product development projects”, Procedia CIRP, Vol. 70, pp. 29-34. https://doi.org/10.1016/j.procir.2018.01.006

Thompson, M. K., Moroni, G. and Vaneker, T. (2016), "Design for additive manufacturing: trends, opportunities, considerations, and constraints", CIRP Annals - Manufacturing Technology, Vol. 65, pp. 737-760. http://dx.doi.org/10.1016/j.cirp.2016.05.004

Weller, C., Kleer, R. and Piller, F. T. (2015), "Economic implications of 3D printing: Market structure models in light of additive manufacturing revisited", International Journal of Production Economics, Vol. 164, pp. 43-56. https://doi.org/10.1016/j.ijpe.2015.02.020

Yeh, C.-C. and Chen, Y.-F. (2018), "Critical success factors for adoption of 3D printing”, Technological Forecasting and Social Change, Vol. 132, pp. 209-216. https://doi.org/10.1016/j.techfore.2018.02.003

Zadnik, Ž., Karakašić, M., Kljajin, M. and Jožef D. (2009), "Function and funcionality in the conceptual design process", Journal of Mechanical Engineering, Vol. 55 No. 7-8, pp. 455-471. 